\title{
CORRESPONDENCE
}

\section{Reply to comment on coronary artery disease and hypertension in a non-selected spinal cord injury patient population (letter to the Editor)}

Spinal Cord Series and Cases (2016) 2, 16029; doi:10.1038/ scsandc.2016.29; published online 17 November 2016

Stillman et al. ${ }^{1}$ finds the methodology of the article 'Coronary artery disease and hypertension in a non-selected spinal cord injury patient population' problematic because it is based on data stemming from reviews of medical record and/or patient interviews, which they consider fundamentally untrustworthy. They imply that the study, as many other studies aiming to describe rates of $\mathrm{CAD}$ among people with $\mathrm{SCl}$, is based on data the objectivity of which is inadequate. It also implies that the data are not valid and clinically meaningful.

We believe that the data in the article are of the highest reliability that can be achieved retrospectively, that they are suitable for comparison with the published data on the general population, with which it was compared, and are at least as trustworthy, valid and clinically meaningful as any data that Stillman et al. ${ }^{1}$ use in their arguments.

We think that Stillman et al. ${ }^{1}$ base their arguments on a wrong interpretation of what is clinically meaningful. In our view, clinically meaningful data underlie a medical problem that causes morbidity, disability or death. By contrast, data that underlie a condition followed by anatomical or physiological changes, without evidence of morbidity, disability or death, should not be considered clinically meaningful.

Stillman et al. ${ }^{1}$ claim that medical records are not reliable because we have no idea how coronary ischemia feels to people with absent or impaired sensation, and therefore we do not know that people with $\mathrm{SCl}$ are being appropriately evaluated for asymptomatic or even symptomatic heart disease. They add that chronic CAD may not appear on electrocardiography or enzymatic analysis, and that therefore we may have missed clinically significant CAD, and that physicians caring for injured individuals, and those individuals themselves, may be unaware of progressive or accelerated atherogenesis.

But Stillmanet al. ${ }^{1}$ did not show any evidence that $\mathrm{SCl}$ patients who allegedly suffer from hidden CAD experience morbidity, disability or death caused by CAD, more than do asymptomatic persons of the general population. They did not present evidence for the real difference between the prevalence of hidden CAD in the general population (as a benchmark) and in the scrupulously followed up population described in the article. There is no basis for their belief that the documentation of hypertension in the general population is more reliable than that of a population that is being followed up for life in a specialized $\mathrm{SCl}$ unit, where blood pressure is meticulously measured over years. They have no indication that the data based on regular examinations in a leading rehabilitation hospital are less reliable than the data published for the general population, which are based on information obtained from respondents who were asked if they had ever been told by a doctor or other health professional that they had CAD or $\mathrm{HT}^{2}{ }^{2}$ Their citation that heart disease emerges as one of the lead causes of mortality in chronic $\mathrm{SCl}$ is not based on more reliable information either. It is based neither on postmortem pathological findings that could prove that CAD was the cause of death, nor on clinical data describing morbidity or disability caused by CAD, but on death certificates of $\mathrm{SCl}$ patients, which the authors of the cited reference consider to be of 'relatively poor quality of cause of death data and reporting practices. ${ }^{3}$

The last argument of Stillman et al. ${ }^{1}$ is based on their own experience with poor evaluation of 108 American $\mathrm{SCl}$ patients in the community. We hope that their findings do not represent the entire US health system. In any case, they have not provided any indication that $\mathrm{SCl}$ patients are evaluated differently from the general population in the same places, nor are they able to draw inferences from that study about other places. We know for certain that the approach of the primary care physician they describe is not that of the physicians employed at Loewenstein Rehabilitation Hospital, and we are confident that this is not the approach in $\mathrm{SCl}$ units with which we are familiar in Europe and in North America.

\section{COMPETING INTERESTS}

The authors declare no conflict of interest.

Elena Aidinoff ${ }^{1,2}$, Vadim Bluvshtein ${ }^{1,2}$, Uri Bierman ${ }^{2}$ Ilana Gelernter ${ }^{1}$, Lilach Front ${ }^{2}$ and Ámiram Catz ${ }^{1,2}$

${ }^{1}$ Faculty of Medicine, Department of Rehabilitation, and School of Mathematics, the Statistical Laboratory, Tel Aviv University,

Tel Aviv, Israel and

${ }^{2}$ Department of Spinal Rehabilitation, Loewenstein Rehabilitation Hospital, Raanana, Israel

Correspondence: A Catz (amcatz@post.tau.ac.il)

\section{REFERENCES}

1 Stillman MD, Williams S, Graves D. Problematic methodology. Spinal Cord Ser Cases 2016; 2: 16028

2 Schiller JS, Lucas JW, Peregoy JA. National Center for Health Statistics Summary, health statistics for US adults: National Health Interview Survey, 2011. Vital Health Stat 2012; 10: 19-106.

3 NSCISC Natioal Spinal Cord Injury Statistical Center Spinal Cord Injury Mode Systems 2014. Annual Report Complete Public Version 2014 (cited on 22 January 2016). Available at http://www.nscisc.uab.edu/PublicDocuments/reports/ pdf/2014\%20NSCISC\%20Annual\%20Statistical\%20Report\%20Complete\%20Public \%20Version.pdf. 